\title{
Aberrant Nuclear Localization and Gene Mutation of $\beta$-catenin in Low-Grade Adenocarcinoma of Fetal Lung Type: Up-Regulation of the Wnt Signaling Pathway May Be a Common Denominator for the Development of Tumors that Form Morules
}

Yukio Nakatani, M.D., Katsuhiko Masudo, M.D., Yohei Miyagi, M.D., Yoshiaki Inayama, M.D.,

Naomi Kawano, M.D., Yukichi Tanaka, M.D., Keisuke Kato, M.D., Takaaki Ito, M.D., Hitoshi Kitamura, M.D., Yoji Nagashima, M.D., Shoji Yamanaka, M.D., Nobuo Nakamura, M.D., Jinyu Sano, M.D., Nobuo Ogawa, M.D., Naoki Ishiwa, M.D., Kenji Notohara, M.D., Milan Resl, M.D., Eugene J. Mark, M.D.

Division of Anatomic and Surgical Pathology (YN, KM, YI, NK), Hospital of Yokohama City University, and Department of Pathology (TI, HK, YNAG, SY), Yokohama City University School of Medicine, Yokohama, Japan; Clinical Research Laboratory (YM), Kanagawa Prefectural Cancer Center, Yokohama, Japan; Department of Pathology (YT, KK), Kanagawa Prefectural Children's Medical Center, Yokohama, Japan; Department of Pathology, Yokohama Citizen's Hospital (NN, JS), Yokohama, Japan; Department of Surgery (NO, NI), Kanagawa Prefectural Cardiovascular and Respiratory Center, Yokohama, Japan; Department of Pathological Research (KN), Okayama University Graduate School of Medicine and Dentistry, Okayama, Japan; Department of Pathology (MR), Charles University Medical School, Hradec Kralove, Czech Republic; and Department of Pathology, Massachusetts General Hospital, and Harvard Medical School (EJM), Boston, Massachusetts

The salient histopathologic features of low-grade adenocarcinoma of the fetal lung type (L-FLAC)/welldifferentiated fetal adenocarcinoma (WDFA) include complex glandular structures and morules with biotin-rich optically clear nuclei. Interestingly, these characteristic features are shared by the cribriformmorular variant of papillary thyroid carcinoma, whose morphology is identical to that of familial adenomatous polyposis (FAP)-associated thyroid carcinoma. Furthermore, the single reported case of lung cancer associated with FAP was L-FLAC/WDFA. These observations lead us to hypothesize that up-regulation of the Wnt signaling pathway underlies the development of L-FLAC/WDFA. To verify this hypothesis, 11 cases of L-FLAC/WDFA, including the one FAPassociated case, eight cases of high-grade adenocarcinoma of the fetal lung type (H-FLAC), 24 cases of conventional pulmonary adenocarcinoma (CAC), and 13 fetal lungs were immunostained for $\beta$-catenin. All cases of L-FLAC/WDFA showed predominantly aber-

Copyright (C) 2002 by The United States and Canadian Academy of Pathology, Inc.

VOL. 15, NO. 6, P. 617, 2002 Printed in the U.S.A.

Date of acceptance: February 14, 2002.

Presented at the 90th General Meeting of the Japanese Society of Pathology, Tokyo, Japan, April 5-7, 2001.

Address reprint requests to: Yukio Nakatani, M.D., Department of Pathology, Yokohama City University Medical Center, 4-57 Urafume, Minami-ku, Yokohama 232-0024, Japan; e-mail: ynak@med.yokohama-cu.ac.jp; fax: 011-81-45-253-5383. rant nuclear/cytoplasmic expression, especially in budding glands and morules, whereas six of eight cases $(75 \%)$ of H-FLAC and all but one case $(96 \%)$ of CAC showed predominantly membranous expression. Fetal lungs showed nuclear/cytoplasmic expression restricted to the distal branching airway epithelium. Mutational analysis of exon 3 of the $\beta$-catenin gene in five sporadic cases of L-FLAC/WDFA showed a point mutation at codon 34 and codon 37 in two cases, respectively. The present study indicates that upregulating disturbances in the Wnt signaling pathway, including mutation of the $\beta$-catenin gene, underlie tumorigenesis of L-FLAC/WDFA. The expression pattern of $\beta$-catenin in L-FLAC/WDFA resembles that of the developing fetal lung airway. With the expression pattern of $\boldsymbol{\beta}$-catenin as a marker, most cases of H-FLAC as well as CAC appear to have different oncogenic pathways from cases of L-FLAC/WDFA. The present study together with other available data also suggests that abnormal up-regulation of the Wnt signaling pathway may be a common denominator for the development of tumors with morular formation from a variety of anatomic sites.

KEY WORDS: Adenocarcinoma of the fetal lung type, APC gene, $\beta$-catenin mutation, Biotin-rich optically clear nucleus, Cribriform-morular variant of papillary thyroid carcinoma, Wnt signaling pathway.

Mod Pathol 2002;15(6):617-624 
Low-grade adenocarcinoma of the fetal lung type (L-FLAC)/well-differentiated fetal adenocarcinoma (WDFA) was originally reported in 1982 as pulmonary blastoma lacking sarcomatous features (pulmonary endodermal tumor resembling fetal lung) (1). Subsequent studies clarified that L-FLAC/ WDFA is a relatively indolent tumor most prevalent in the fourth decade of life with a mild female predominance and a death rate of about $10 \%(2-4)$. The salient histopathologic features of L-FLAC/ WDFA are complex glandular structures with cells rich in glycogen, resembling the fetal lung airway epithelium or endometrioid carcinoma and morular formation with optically clear nuclei $(\mathrm{OCN})$ that are rich in biotin $(4,5)$. High-grade adenocarcinoma of the fetal lung type (H-FLAC) was separated from L-FLAC/WDFA because of different clinicopathologic features, including significantly worse prognosis (4), although both tumors have histologic features resembling fetal lung and can be confused with each other (6).

With the progress in our understanding of LFLAC/WDFA, it has become apparent that tumors with an almost identical histopathologic pattern of complex glandular structures and morular formation with biotin-rich OCN occur in several guises, including endometrioid carcinoma of the ovary (7), thyroid papillary carcinoma (8-10), adenoma of the gallbladder (11), pancreatoblastoma (12), and adenoma of the colon (13). Although female sex hor mones were initially implicated as a common denominator for the development of tumors belonging to the "OCN family" (5), this hypothesis has not been verified $(5,13)$.

Sporadic cases of thyroid papillary carcinomas with morules containing OCN have been termed to be cribriform-morular variant (14), and it has been recognized that an identical morphology also occurs in familial adenomatous polyposis (FAP)associated thyroid carcinoma $(15,16)$. The single lung cancer so far reported in association with FAP has been L-FLAC/WDFA (17). Based on these observations, we hypothesized that the development of L-FLAC/WDFA is closely related to abnormal up-regulation of the Wnt signaling pathway (18).

The Wnt signaling pathway participates in embryonic development and leads to tumor formation when deranged (18). The Wnt signal is transmitted to the nucleus by cytoplasmic $\beta$-catenin, which activates target genes by forming complexes with lymphoid enhancer factor/T-cell factor (LEF/TCF) within the nucleus. In the normal state, cytoplasmic $\beta$-catenin is maintained at a low level because of its degradation by a multiprotein complex, including the adenomatous polyposis coli (APC) tumor suppressor protein. In FAP, mutational inactivation of the APC results in reduced degradation of $\beta$-catenin and nuclear accumulation of the protein, leading to activation of oncogenic target genes such as $c$-myc and cyclin Dl. Furthermore, $\beta$-catenin degradation also may be blocked by mutation of $\beta$-catenin, which is present in approximately half of the colorectal cancers that lack APC mutations, and thus may play a role in tumorigenesis (19). Because aberrant nuclear/ cytoplasmic localization of $\beta$-catenin as a final common event of either APC or $\beta$-catenin mutations can be detected immunohistochemically (20), we investigated the localization of $\beta$-catenin in L-FLAC/WDFA as well as in related lung tumors and developing fetal lungs. Furthermore, mutational analysis of the $\beta$-catenin gene was performed in five cases of L-FLAC/WDFA.

\section{MATERIALS AND METHODS}

Seven surgically resected L-FLAC/WDFAs, eight H-FLACs, 24 conventional adenocarcinomas, and 13 fetal lungs from cases of spontaneous abortion and stillbirth were collected from the files of our departments and from the consultation files of one of the authors (E.J.M.). In addition, four cases of L-FLAC/WDFA were kindly provided by Drs. S. Kuwao, K. Kashima, and S. Hamazaki of Japan, as well as Drs. W.S. Hwang and S.K. Field of Canada. The clinical and pathologic features of most of the LFLAC/WDFA and H-FLAC cases in the present series have been described elsewhere $(4,17)$. Of the 24 conventional adenocarcinomas, seven were welldifferentiated, 13 moderately differentiated, and four poorly differentiated. The gestational age for the 13 fetal lungs ranged from 9 to 26 weeks.

Immunostaining for $\beta$-catenin was performed on formalin-fixed paraffin-embedded tissue sections by the Envision+ technique (DAKO). Antigen retrieval was conducted by heating in an autoclave for 10 minutes. The primary mouse monoclonal anti$\beta$-catenin antibody (1:200, clone 14 ; Transduction Labs, Lexington, KY) was applied to the sections at $4^{\circ} \mathrm{C}$ overnight. Final visualization was carried out by diaminobenzidine.

Mutational analysis of the $\beta$-catenin gene was performed in five sporadic cases of L-FLAC/WDFA, using DNA extracted from three to five 4-mm-thick paraffin sections of a representative tissue block in each case. For the extraction of DNA, the tumor sections were placed in a microtube containing 0.5 mL of a DNA extraction solution (TaKaRa DEXPAT ${ }^{\mathrm{TM}}$, Takara, Otsu, Japan). The mixture was boiled for 10 minutes, centrifuged at 12,000 rpm for 10 minutes, and the supernatant was used as a DNA extract according to the manufacturer's instructions. Next, $5 \mu \mathrm{L}$ of a DNA extract was amplified by polymerase chain reaction (PCR) in a total reaction volume of $50 \mu \mathrm{L}$, containing $10 \mathrm{~mm}$ Tris- $\mathrm{HCl}(\mathrm{pH}$ 9.0), $50 \mathrm{~mm} \mathrm{KCl}, 1.5 \mathrm{~mm} \mathrm{MgCl}_{2}, 50 \mu \mathrm{M}$ of each dNTP, 
$0.5 \mu \mathrm{M}$ primers, and 2.5 U Taq DNA polymerase (Promega, Madison, WI). Two sets of primers were used for nested PCR with final amplification of a 200 -bp fragment of exon 3 of the $\beta$-catenin gene encompassing the region of the GSK- $3 \beta$ phosphorylation site that contains activating mutations. The primer set for the first round of PCR included the forward primer: 5'-CCAATCTACTAA-TGCTAATACTG-3' and the reverse primer: 5'-CTGCATTCTGACTTTCAGTAAGG-3'. The second primer set used was the forward primer: 5'-ATGGAACCAGACAGAAAAGC-3' and the reverse primer: 5'-GCTACTTGTTCTTGAGTGAAG-3'. Following an initial denaturation step at $95^{\circ} \mathrm{C}$ for 5 minutes, 20 cycles of amplification were performed (denaturation at $95^{\circ} \mathrm{C}$ for $30 \mathrm{sec} /$ annealing at $55^{\circ} \mathrm{C}$ for $30 \mathrm{sec} /$ elongation at $72^{\circ} \mathrm{C}$ for $90 \mathrm{sec}$ ), followed by a final elongation step of 5 minutes at $72^{\circ} \mathrm{C}$. Diluted external PCR products ( $2 \mu \mathrm{L} ; 1: 100)$ were submitted to the second round PCR for 30 cycles using the same temperature profile. The PCR products were sequenced directly by the same primers as those used for the second round of PCR amplification with the dye terminator cycle sequencing method and the CEQ2000 multi-capillary DNA sequencing system (Beckman Coulter, Fullerton, CA). Because the direct sequence analysis showed heterozygous substitution mutations, those fragments demonstrating heterozygous sequence profiles were subcloned into pGem-T-easy plasmid vector (Promega, Madison, $\mathrm{WI}$ ), and more than 10 clones were sequenced with both M13 forward and reverse universal sequencing primers to confirm/the sequence.

\section{RESULTS}

Intense membranous expression pattern (MP) of $\beta$-catenin was observed in the normal bronchial epithelium present in the non-neoplastic portion of the tumor sections. It was weakly observed in the normal alveolar lining cells as well, whereas reactive type II pneumocytes in the vicinity of the tumor growth commonly showed the aberrant nuclear/ cytoplasmic expression pattern (NCP) (Fig. 1). All 11 cases of L-FLAC/WDFA, including the one FAPassociated case (17), predominantly exhibited NCP. NCP was especially prominent in cells comprising the peripherally budding glands and morules, including cells with optically clear nuclei (Fig. 2). MP was markedly reduced or absent in the neoplastic cells of all L-FLAC/WDFA cases. Of eight cases of H-FLAC, six showed predominantly MP and two showed NCP (Fig. 3). One of the tumors with NCP exhibited histologic features intermediate between L-FLAC/WDFA and H-FLAC. In 24 cases of conventional adenocarcinoma, MP was predominant in all but one case (96\%). However, poorly differentiated

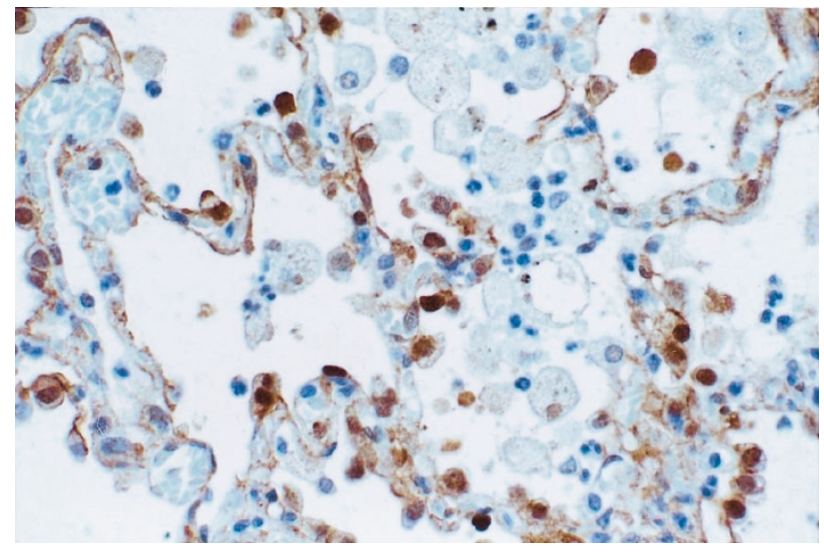

FIGURE 1. Nuclear/cytoplasmic expression pattern of $\beta$-catenin can be seen in reactive type II pneumocytes.

adenocarcinomas showed reduced expression of $\beta$-catenin. Only one case of moderately differentiated adenocarcinoma showed NCP predominantly. In eight cases (33\%), NCP was focally seen as well, often in the peripheral portion of the tumors abutting the surrounding stroma. Stromal cells within the surrounding young fibrous tissue often showed NCP. In the 13 fetal lungs, the peripheral branching airway epithelium predominantly showed NCP from 9 to 22 weeks of gestation, while all airway and respiratory epithelia, at later stages of gestation, exhibited only MP (Fig. 4). The proximal airway epithelium constantly showed MP throughout the gestational periods examined. In the lung at 9 weeks' gestation, many of the primitive stromal cells surrounding the peripheral branching airway also showed NCP (Fig. 4A).

Direct sequence analysis of the PCR products of $\beta$-catenin gene exon 3 in Case 9 and Case 6 demonstrated a mixed pattern of the wild-type and mutant peaks. Specifically, Case 9 exhibited a TCT (Ser) to TGT (Cys) transversion at codon 37 (Fig. 5A) and Case 6 a GGA (Gly) to GTA (Val) transversion at codon 34. The remaining three cases showed no abnormality. Further sequence analysis of the subcloned PCR fragments confirmed that both wild and mutated alleles actually existed. The confirmed sequences of the mutated alleles are shown in Fig. $5 \mathrm{~B}$.

\section{DISCUSSION}

To the best of our knowledge, no abnormality of the Wnt signaling pathway comparable with that detected in L-FLAC/WDFA in this study has been reported previously in human lung cancers. Retera and associates investigated 101 cases of non-small cell lung cancers and noted an association of reduced expression of $\beta$-catenin with an unfavorable prognosis, but they did not refer to aberrant nuclear localization of $\beta$-catenin (21). Pirinen and associ- 


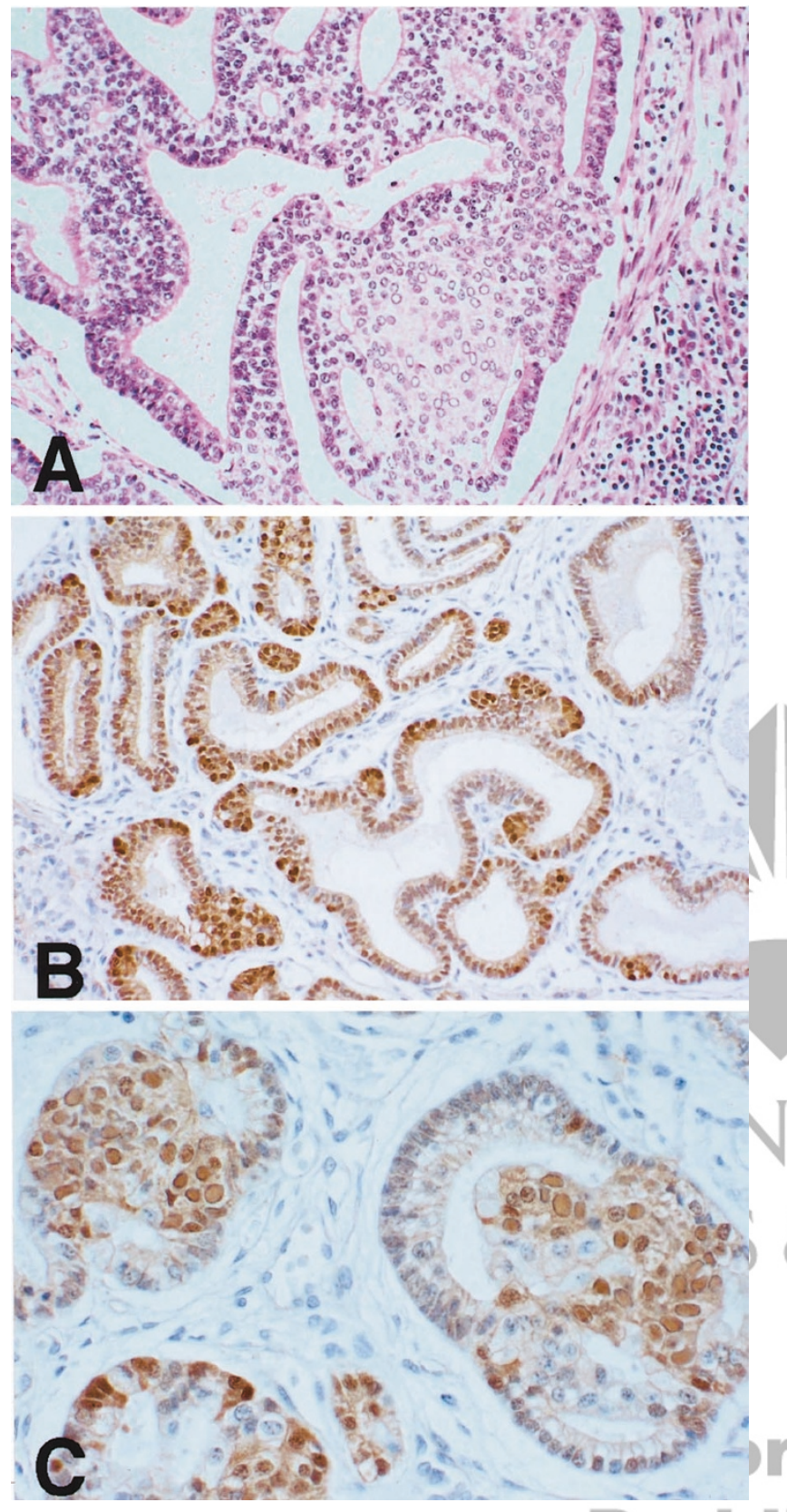

FIGURE 2. L-FLAC/WDFA. (A) Complex glands resembling fetal lung airway epithelium with morular formation. (B) Note predominant localization of the nuclear/cytoplasmic expression pattern of $\beta$-catenin in budding glands and morules. (C) Optically clear nuclei in morules are immunoreactive for $\beta$-catenin.

ates recently reported nuclear/cytoplasmic expression for $\beta$-catenin in only 16 (7\%) of 261 non-small cell lung cancers (22). Sunaga and associates studied 46 cultured cell lines of lung cancer as well as 47 resected lung cancer specimens and found mutations in exon 3 of the $\beta$-catenin gene in only $1(2 \%)$ of the 46 cell lines and 2 (4\%) of the 47 lung tumors (23). Moreover, in the present study, nuclear/cytoplasmic expression of $\beta$-catenin was seen only rarely as the predominant pattern in conventional adenocarcinomas of the lung, which was consistent with the results of the previous studies, indicating
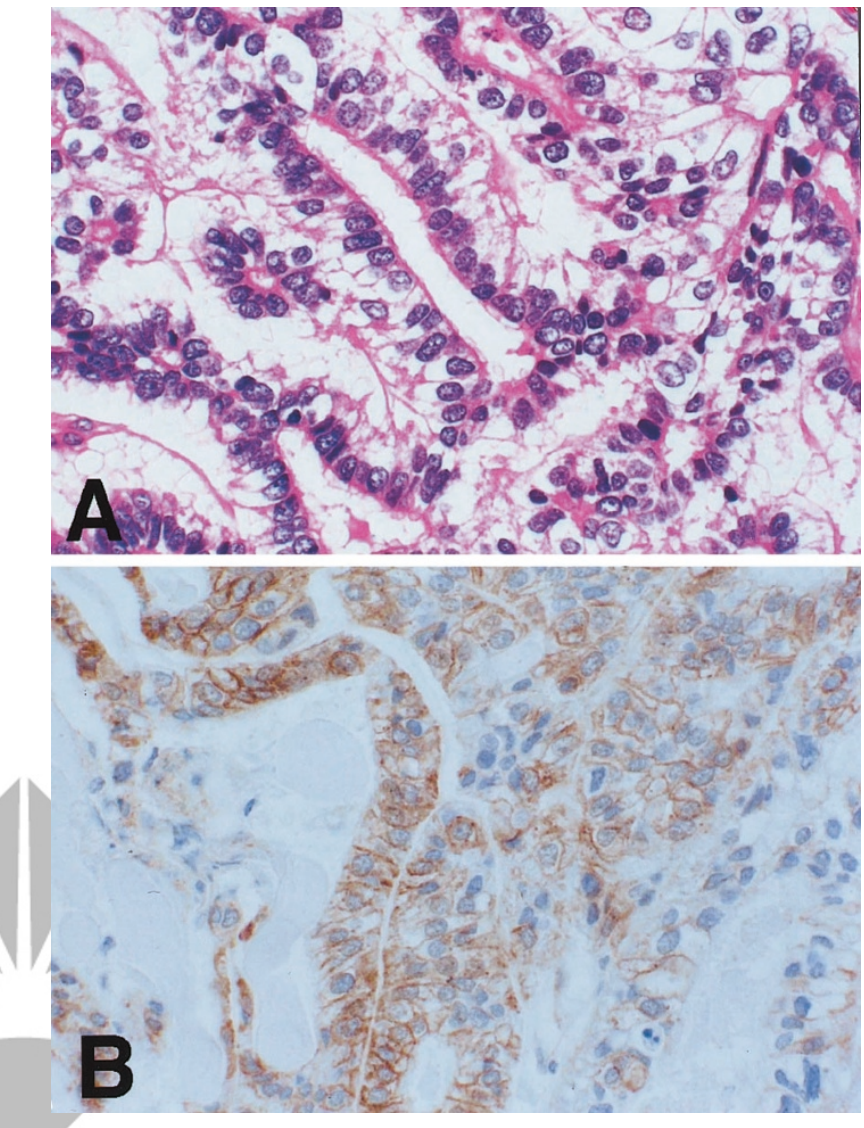

FIGURE 3. H-FLAC. (A) Complex glycogen-rich glands resemble those of L-FLAC/WDFA, but show more significant nuclear atypia. (B) Predominantly membranous expression pattern of $\beta$-catenin can be seen.

\section{DIS}

that abnormality of the Wnt signaling pathway may play a relatively minor role or none at all in the tumorigenesis of conventional lung cancers. In contrast, all 11 cases of L-FLAC/WDFA in the present study showed predominantly nuclear/cytoplasmic expression of $\beta$-catenin, suggesting that the development of this unique lung tumor may be closely associated with abnormality of the Wnt signaling pathway. In support of this is our finding of mutations in the phosphorylation sequence for GSK- $3 \beta$ in exon 3 of the $\beta$-catenin gene in two cases of L-FLAC/WDFA. Mutations in these phosphorylation sites lead to failure of $\beta$-catenin degradation by GSK- $3 \beta$, resulting in $\beta$-catenin accumulation and the subsequent activation of oncogenic target genes (18). Mutational inactivation of the APC gene, another critical event leading to up-regulation of the Wnt signal transduction, may be partly responsible for the development of those sporadic cases of LFLAC/WDFA that lack $\beta$-catenin mutations, as has been demonstrated recently in a sporadic case of the cribriform-morular variant of papillary thyroid carcinoma (24). Mutations of a tumor suppressor gene PTEN are also possible because inactivation of PTEN leads to nuclear accumulation of $\beta$-catenin 


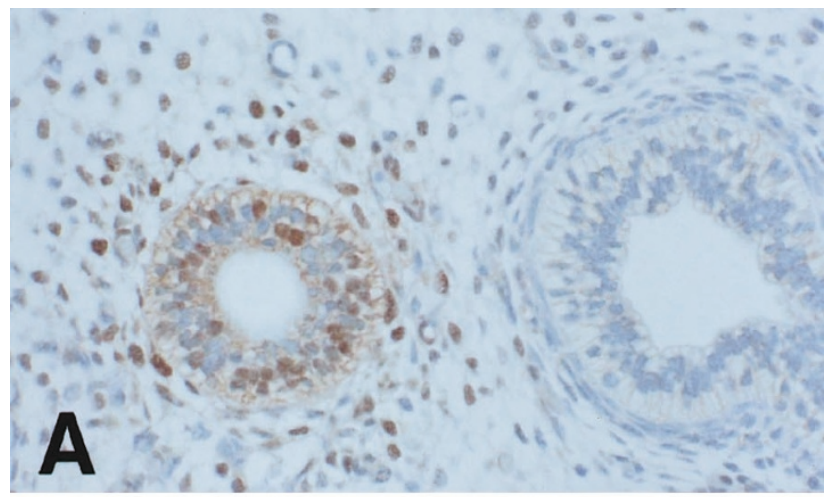

A
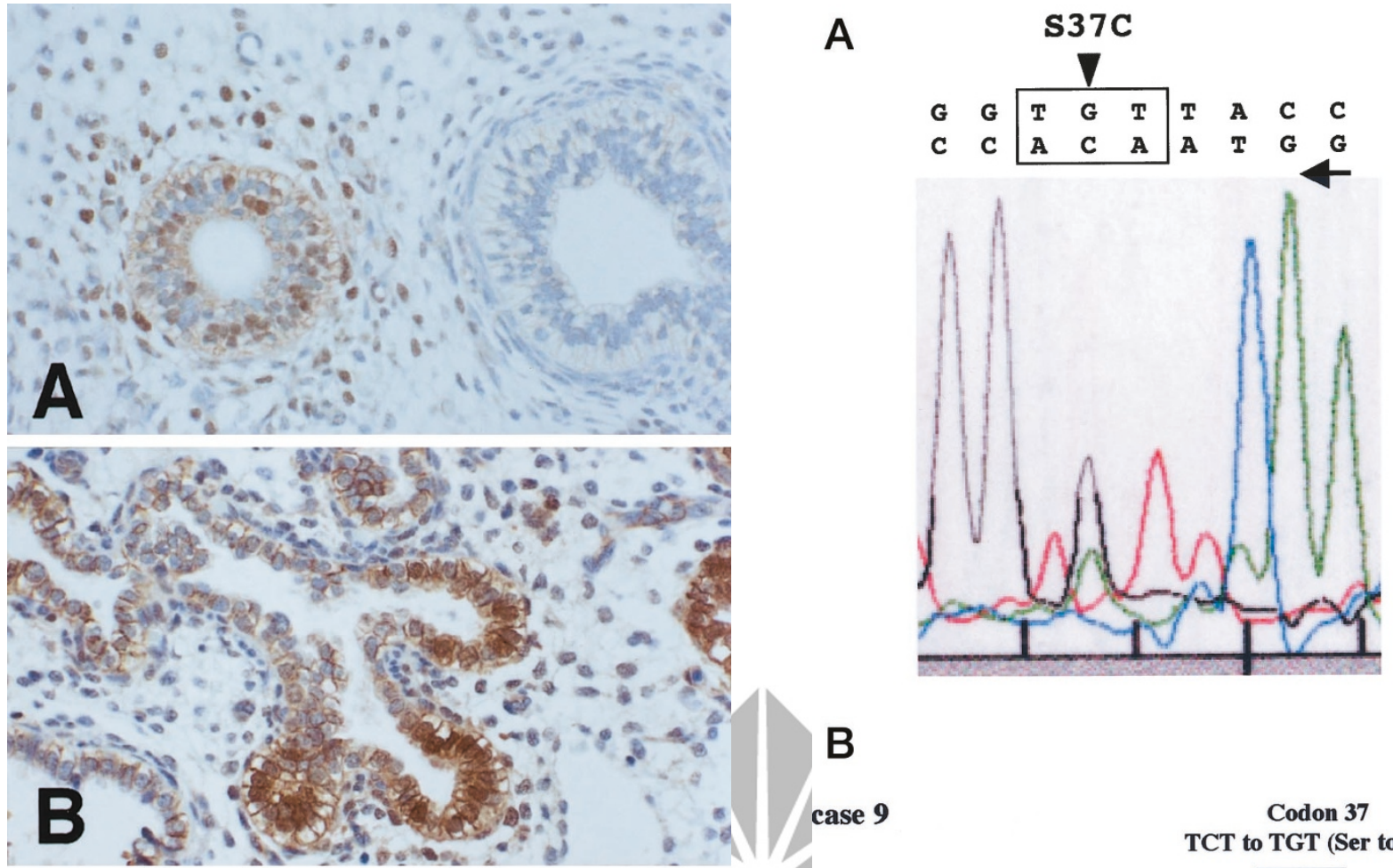

B

Codon 37

TCT to TGT (Ser to Cys)
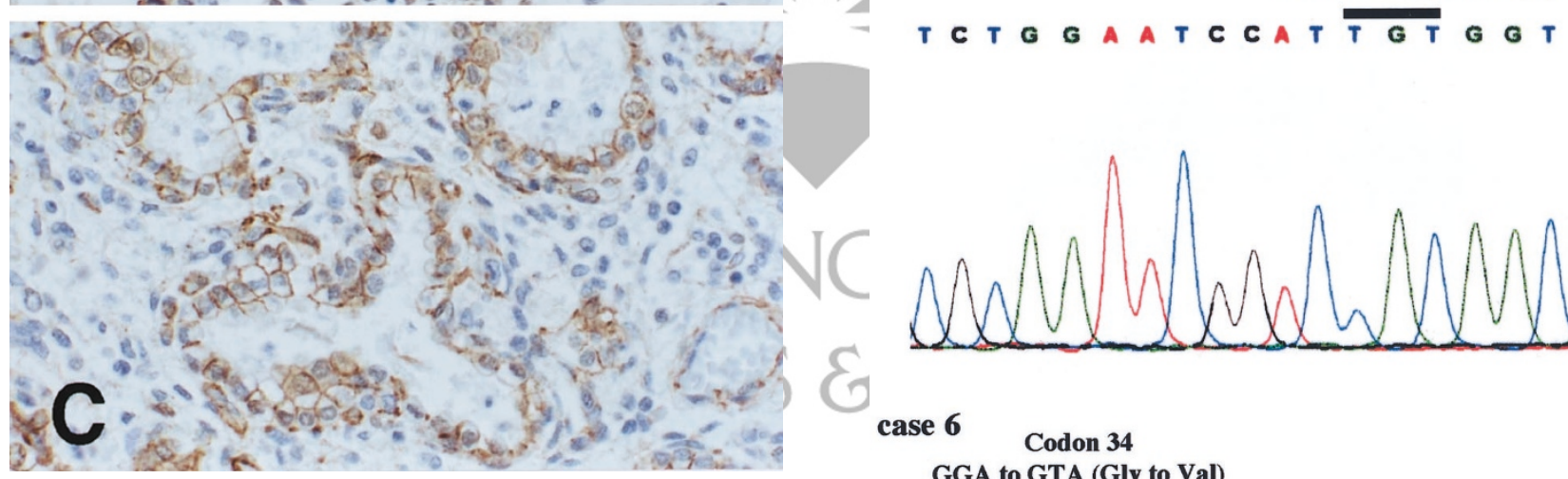

FIGURE 4. Fetal lungs at various gestational periods. (A) Nine weeks. Note nuclear/cytoplasmic expression pattern of $\beta$-catenin both in the branching airway epithelium and primitive stromal cells surrounding it. (B) Seventeen weeks. Note $\beta$-catenin immunostaining with a predominant membranous expression pattern in the proximal airway and nuclear/cytoplasmic expression pattern in the distal branching epithelium. (C) Twenty-three weeks. Only the membranous expression pattern of $\beta$-catenin can be seen.

and TCF transcriptional activation (25). Further study is required to determine precisely which gene mutations are involved in what proportions in the abnormal up-regulation of the Wnt signaling pathway in L-FLAC/WDFA.

With the expression pattern of $\beta$-catenin as a marker, H-FLAC appears to be closer to conventional adenocarcinoma than to L-FLAC/WDFA despite its morphologic similarity to L-FLAC. This observation lends support to the concept of discrimination of H-FLAC from L-FLAC/WDFA (4), suggesting that most if not all H-FLAC cases may arise de novo rather than as a progression from L-FLAC. This is in keeping with the significant dif-
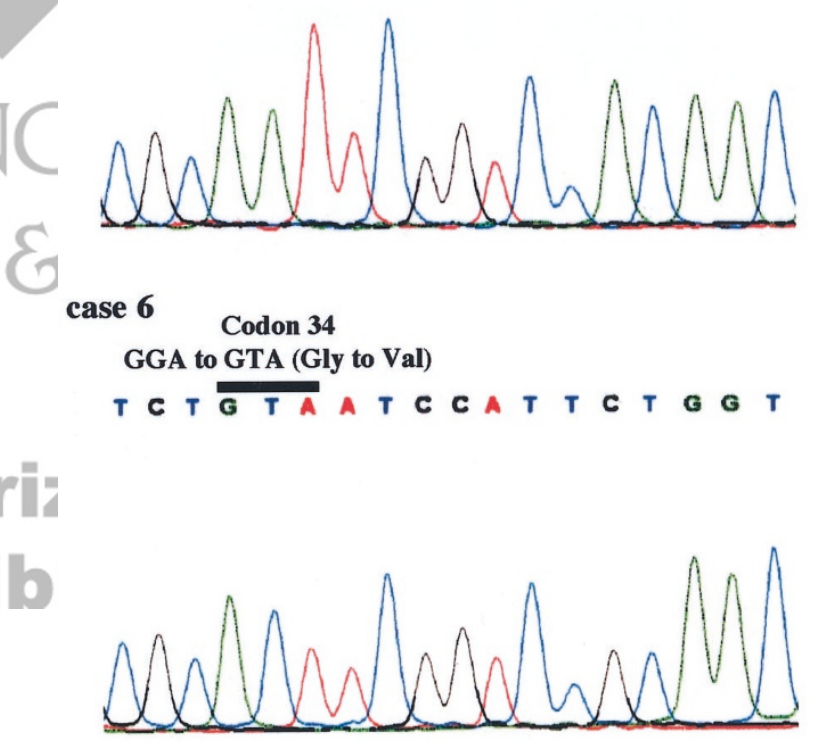

FIGURE 5. Sequence analysis for exon 3 of the $\beta$-catenin gene in LFLAC/WDFA. (A) Sequencing chromatogram in Case 9 demonstrating a mixed pattern of the wild-type (TCT) and mutant (TGT) peaks at codon 37. The mutation results in an amino acid change of serine to cysteine (S37C). The nucleotide sequence is shown above the chromatogram. Codon 37 is boxed, and the mutated guanine nucleotide is indicated by an arrow head. The horizontal arrow demonstrates the direction of sequencing. (B) Sequence analysis of the subcloned PCR fragments confirming the presence of the mutated alleles in Case 9 and Case 6.

ference in gender and age distribution and natural history of the two subtypes (4). We have previously proposed the hypothesis that what have been reported as biphasic pulmonary blastoma consist of 
those derived from dedifferentiation of L-FLAC/ WDFA and those from dedifferentiation of H-FLAC (4). Investigation of abnormality of the Wnt signaling pathway in biphasic pulmonary blastomas certainly will contribute to understanding their relationship to L-FLAC/WDFA and H-FLAC.

Because most cases of L-FLAC/WDFA so far reported are likely to have been sporadic, except for the one FAP-associated case (17), some postnatal mutagenic factor(s) are likely to play an important role in tumorigenesis. Thus, it is noteworthy that $76 \%$ of patients with L-FLAC/WDFA have had a history of smoking (4). Tsujiuchi and associates recently reported frequent mutations of the $A P C$ and $\beta$-catenin genes in pulmonary adenocarcinomas induced by $N$-nitrosobis(2-hydroxypropyl)amine (BHP) in rats (26). BHP is a carcinogenic compound postulated to be an intermediate metabolite of one of the closely related $\mathrm{N}$-nitrosoamines that are contained in cigarette smoke (27).

Another interesting aspect of the aberrant nuclear/cytoplasmic expression of $\beta$-catenin in L-FLAC/ WDFA is its predominant localization in branching glands and morules. An identical pattern of aberrant $\beta$-catenin expression in branching glands has been noted in colorectal adenoma/carcinoma (28), a neoplasm that is well known for its frequent $\beta$-catenin mutations (19). This pattern of $\beta$-catenin expression is analogous to that seen in invagination of endoderm during embryogenesis (29). Everhart and Argani recently reported nuclear localization of $\beta$-catenin in pulmonary acinar buds and mesenchymal cells surrounding the acini in the fetus ( $\overline{3} 0)$, which concurs with our finding in the present study. Branching of the distal airways during fetal lung development may be regarded as an extension of endodermal invagination, which is consistent with the finding of nuclear/cytoplasmic expression of $\beta$-catenin in branching airway epithelium. $\beta$-catenin gene mutations and extracellular matrix molecules in the microenvironment around the tumor may be affecting expression of $\beta$-catenin and its distribution in nucleus and cytoplasm in these tumors (28). The signaling pathway involving growth factors and integrin-linked kinase may be a link between the extracellular matrix and upregulation of the Wnt signaling pathway $(25,31)$. The nuclear/cytoplasmic expression of $\beta$-catenin in reactive type II pneumocytes suggests that the Wnt signaling pathway also may play a role in cell proliferation in response to alveolar injury. Thus both tumorigenesis of L-FLAC/WDFA and regenerative change of the adult respiratory epithelium appear to resemble embryogenesis of the lung with respect to the pattern of $\beta$-catenin expression. Furthermore, the NCP in stromal cells of fibrous tissue around invasive tumors and in neoplastic cells in the invasive front of conventional adenocarcino- mas may be a recapitulation of early pulmonary embryogenesis.

Our results as well as published data suggest that up-regulating disturbances in the Wnt signaling pathway is a common denominator for the development of tumors with morular formation from a variety of anatomic sites. Besides the cribriform-morular variant of papillary thyroid carcinoma/FAP-associated thyroid carcinoma and colonic adenoma/adenocarcinoma, which show mutations of the $A P C$ or $\beta$-catenin genes, recent studies have demonstrated aberrant nuclear/cytoplasmic expression of $\beta$-catenin in association with $\beta$-catenin gene mutations in tumors with morular formation, such as endometrioid carcinoma of the ovary (32) and adenoma of the gallbladder (33). Although morules within adenoacanthoma of the uterus usually do not show OCN, endometrioid carcinoma $(34,35)$, especially adenoacanthoma (36), frequently show $\beta$-catenin gene mutations. Based on this hypothesis, we investigated pancreatoblastoma, which shows morules with biotin-rich OCN (12). We found that this tumor constantly shows aberrant nuclear/cytoplasmic expression of $\beta$-catenin with two of the five cases examined showing missense mutations of the $\beta$-catenin gene (44). We also found aberrant nuclear/cytoplasmic expression of $\beta$-catenin in all 13 sporadic cases of cribriform-morular variant of papillary thyroid carcinoma examined, three of which showed $\beta$-catenin gene mutations as well (37). Apparently not all types of glandular tumors with $\beta$-catenin or APC mutations show morular formation, as pituitary adenoma (38) and hyperplastic fundic gland polyp (39), which may harbor $\beta$-catenin mutations, do not do so. Colonic adenoma/adenocarcinoma with common $\beta$-catenin mutations (19) only rarely exhibit morular formation (13). Accordingly, an upregulating disturbance in the Wnt signaling pathway is probably a prerequisite condition, and some other factor(s) must also underlie the morular formation.

The clinically significant feature common to most of these tumors with morular formation is that they are either benign $(11,13)$ or of low-grade malignancy with a relatively favorable prognosis $(3,4,8$, $32,35)$. This is in sharp contrast to another group of tumors with frequent $\beta$-catenin or APC mutations and high-grade malignancy with a poor prognosis, such as hepatoblastoma $(40,41)$ and anaplastic carcinoma of the thyroid (42). Further study is necessary to clarify the mechanism by which mutations of the $\beta$-catenin and APC genes are related to the grade of malignancy.

\section{ADDENDUM}

After submission of the manuscript, Abraham and associates reported frequent $\beta$-catenin gene mutations in sporadic pancreatoblastomas (43). 
Acknowledgments: The authors are grateful to Drs. S. Kuwao, K. Kashima, S. Yokoyama, S. Hamazaki, W.S. Hwang, and S.K. Field for providing their cases. The authors also thank Dr. M. Kanisawa for his pertinent advice and help and the histology technical staff for their assistance.

\section{REFERENCES}

1. Kradin RL, Young RH, Dickersin GR, Kirkham SE, Mark EJ. Pulmonary blastoma with argyrophil cells and lacking sarcomatous features (pulmonary endodermal tumor resembling fetal lung). Am J Surg Pathol 1982;6:165-72.

2. Nakatani Y, Dickersin GR, Mark EJ. Pulmonary endodermal tumor resembling fetal lung. A clinicopathologic study of five cases with immunohistochemical and ultrastructural characterization. Hum Pathol 1990;21:1097-107.

3. Koss MN, Hochholzer L, O'Leary T. Pulmonary blastomas. Cancer 1991;67:2368-81.

4. Nakatani Y, Kitamura H, Inayama Y, Kamijo S, Nagashima Y, Shimoyama K, et al. Pulmonary adenocarcinomas of the fetal lung type: a clinicopathologic study indicating differences in histology, epidemiology, and natural history of lowgrade and high-grade forms. Am J Surg Pathol 1998;22:399 411.

5. Nakatani Y, Kitamura H, Inayama Y, Ogawa N. Pulmonary endodermal tumor resembling fetal lung. The optically clear nucleus is rich in biotin. Am J Surg Pathol 1994;18:637-42.

6. Kodama T, Koide T, Shimosato Y, Naruke T, Watanabe S, Shimase J. Six cases of well-differentiated adenocarcinoma simulating fetal lung tubules in pseudoglandular stage. Comparison with pulmonary blastoma. Am J Surg Pathol 1984;8:735-44.

7. Tsujimoto M, Noguchi M, Takei I. Immunohistochemical and electron microscopic study of the intranuclear inclusion bodies containing biotin in the ovarian endometrioid carcinoma. J Clin Electron Microsc 1991;24:783-4.

8. Yamashita T, Hosoda Y, Kameyama K, Aiba M, Ito K, Fujimoto Y. Peculiar nuclear clearing composed of microfilaments in papillary carcinoma of the thyroid. Cancer 1992; 70:2923-8.

9. Tsang WYW, Chan JK. Peculiar nuclear clearing composed of microfilaments in papillary carcinoma of the thyroid [letter]. Cancer 1993;72:300.

10. Okamoto Y, Kashima K, Daa T, Yokoyama S, Nakayama I. Morule with biotin-containing intranuclear inclusions in thyroid carcinoma. Pathol Int 1995;45:573-9.

11. Takei K, Watanabe H, Itoi T, Sato T. p53 and Ki-67 immunoreactivity and nuclear morphometry of "carcinoma-inadenoma" and adenoma of the gall-bladder. Pathol Int 1996; 46:426-35.

12. Tanaka Y, Ijiri R, Yamanaka S, Kato K, Nishihira H, Nishi T, et al. Pancreatoblastoma. Optically clear nuclei in squamoid corpuscles are rich in biotin. Mod Pathol 1998;11:945-9.

13. Sasaki A, Yokoyama S, Arita T, Inomata M, Kashima K, Nakayama I. Morules with biotin-containing optically clear nuclei in colonic tubular adenoma. Am J Surg Pathol 1999;23: 336-41.

14. Cameselle-Teijeiro J, Chan JK. Cribriform-morular variant of papillary carcinoma. A distinctive variant representing the sporadic counterpart of familial adenomatous polyposisassociated thyroid carcinoma? Mod Pathol 1999;12:400-11.

15. Harach HR, Williams GT, Williams ED. Familial adenomatous polyposis associated thyroid carcinoma. A distinct type of follicular cell neoplasm. Histopathology 1994;25:549-61.

16. Soravia C, Sugg SL, Berk T, Mitri A, Cheng H, Gallinger S, et al. Familial adenomatous polyposis-associated thyroid can- cer. A clinical, pathological, and molecular genetics study. Am J Pathol 1999;154:127-35.

17. Wong RP, Hwang W-S, Field SK. Familial adenomatous polyposis and lung cancer. J Surg Oncol 1995;60:213-4.

18. Behrens J. Control of $\beta$-catenin signaling in tumor development. Ann NY Acad Sci 2000;910:21-35.

19. Sparks AB, Morin PJ, Vogelstein B, Kinzler KW. Mutational analysis of the APC/ $\beta$-catenin/Tcf pathway in colorectal cancer. Cancer Res 1998;58:1130-4.

20. Brabletz T, Jung A, Hermann K, Günther K, Hohenberger W, Kirchner T. Nuclear overexpression of the oncoprotein b-catenin in colorectal cancer is localized predominantly at the invasion front. Pathol Res Prac 1998;194:701-4.

21. Retera JMAM, Leers MPG, Sulzer MA, Theunissen PHMH. The expression of $\beta$-catenin in non-small-cell lung cancer. J Clin Pathol 1998;51:891-4.

22. Pirinen RT, Hirvikoski P, Johansson RT, Hollmen S, Kosma VM. Reduced expression of alpha-catenin, beta-catenin, and gamma-catenin is associated with high cell proliferative activity and poor differentiation in non-small cell lung cancer. J Clin Pathol 2001;54:391-5.

23. Sunaga N, Kohno T, Kolligs FT, Fearon ER, Saito R, Yokota J. Constitutive activation of the Wnt signaling pathway by CTNNB1 (beta-catenin) mutations in a subset of human lung adenocarcinomas. Genes Chromosom Cancer 2001;30:31621.

24. Cameselle-Teijeiro J, Ruiz-Ponte C, Loidi L, SuarezPenaranda J, Baltar J, Sobrinho-Simoes M. Somatic but not germline mutation of the APC gene in a case of cribriformmorular variant of papillary thyroid carcinoma. Am J Clin Pathol 2001;115:486-93.

25. Persada S, Troussarda AA, McPheea TR, Mulhollandb DJ, Dedhara S. Tumor suppressor PTEN inhibits nuclear accumulation of $\beta$-catenin and T cell/lymphoid enhancer factor 1-mediated transcriptional activation. J Cell Biol 2001;153: 1161-74.

26. Tsujiuchi T, Tsutsumi M, Sasaki Y, Murahata N, Konishi Y. Mutations of adenomatous polyposis coli and $\beta$-catenin genes dưring progression of lung tumors induced by $\mathrm{N}$-nitrosobis(2-hydropropyl)amine in rats. Cancer Res 2000; 60:6611-6.

27. International Agency for Research on Cancer (IARC). Tobacco smoking. In: IARC monographs on the evaluation of the carcinogenic risk of chemicals to humans, Vol. 38. Lyon, France: IARC Press; 1985. p. 86-392.

28. Kirchner T, Brabletz T. Patterning and nuclear $\beta$-catenin expression in the colonic adenoma-carcinoma sequence. Analogies with embryonic gastrulation. Am J Pathol 2000; 157:1113-21.

29. Logan CY, Miller JR, Ferkovicz MJ, McClay DR. Nuclear beta-catenin is required to specify vegetal cell fates in the sea urchin embryo. Development 1999;126:345-57.

30. Eberhart CG, Argani P. Wnt signaling in human development. Beta-catenin nuclear translocation in fetal lung, kidney, placenta, capillaries, adrenal, and cartilage. Pediatr Dev Pathol 2001;4:351-7.

31. Novak A, Hsu S-C, Leung-Hagesteijn C, Radeva G, Papkoff J, Montesano R, et al. Cell adhesion and the integrin-linked kinase regulate the LEF- 1 and $\beta$-catenin signalling pathways. Proc Natl Acad Sci USA 1998;95:4374-9.

32. Gamallo C, Palacios J, Moreno G, de Mora JC, Suarez A, Armas A. $\beta$-catenin expression pattern in stage I and II ovarian carcinomas. Relationship with $\beta$-catenin gene mutations, clinicopathological features, and clinical outcome. Am J Pathol 1999;155:527-36.

33. Yanagisawa N, Mikami T, Saegusa M, Okayasu I. More frequent $\beta$-catenin exon 3 mutations in gallbladder adenomas than in carcinomas indicate different lineages. Cancer Res 2001;61:19-22. 
34. Fukuchi T, Sakamoto S, Tsuda H, Maruyama K, Nozawa S, Hirohashi S. $\beta$-catenin mutation in carcinoma of the uterine endometrium. Cancer Res 1998;58:3526-8.

35. Schlosshauer PW, Pirog EC, Levine RL, Ellenson LH. Mutational analysis of the CTNNB1 and APC genes in uterine endometrioid carcinoma. Mod Pathol 2000;13:1066-71.

36. Saegusa M, Okayasu I. Frequent nuclear beta-catenin accumulation and associated mutations in endometrioid-type endometrial and ovarian carcinomas with squamous differentiation. J Pathol 2001;194:59-67.

37. Masudo K, Nakatani Y, Inayama Y, Kawano N, Miyagi Y, Tamai S, et al. Cribriform-morular variant of papillary thyroid carcinoma. A pathologic analysis of 15 cases. Proc Jpn Soc Pathol 2001;90:346a.

38. Semba S, Han S-Y, Ikeda H, Horii A. Frequent nuclear accumulation of $\beta$-catenin in pituitary adenoma. Cancer 2001;91:42-8.

39. Abraham SC, Nobukawa B, Giardiello FM, Hamilton SR, Wu T-T. Sporadic fundic gland polyps. Common gastric polyps arising through activating mutations in the $\beta$-catenin gene. Am J Pathol 2001;158:1005-10.
40. Oda H, Imai Y, Nakatsuru J, Hata J, Ishikawa T. Somatic mutations of the APC gene in sporadic hepatoblastomas. Cancer Res 1996;56:3320-3.

41. Jeng YM, Wu MZ, Mao TL, Chang MH, Hsu HC. Somatic mutations of $\beta$-catenin play a crucial role in the tumorigenesis of sporadic hepatoblastoma. Cancer Lett 2000;152:4551.

42. Garcia-Rostan G, Camp RL, Herrero A, Carcangiu ML, Rimm DL, Tallini G. Beta-catenin dysregulation in thyroid neoplasms: down-regulation, aberrant nuclear expression, and CTNNB1 exon 3 mutations are markers for aggressive tumor phenotypes and poor prognosis. Am J Pathol 2001;158:987-96.

43. Abraham SC, Wu T-T, Klimstra DS, Finn LS, Lee J-H, Yeo CJ, et al. Distinctive molecular alterations in sporadic and familial adenomatous polyposis-associated pancreatoblastomas. Frequent alterations in the APC/ $\beta$-catenin pathway and chromosome 11p. Am J Pathol 2001;159:1619-27.

44. Kato K, Notohara K, Hijo H, Nakatami Y, Horie H, Kobayashi $\mathrm{Y}$, et al. Abnormality of the Wmt signaling pathway in pancreatoblastoma and solid-pseudopapillary neoplasm. Proc Jpn Soc Pathol 2002;91:312a.

\section{Book Review}

Nadler S: The Language of Cells: Life as Seen Under the Microscope, 197 pp, New York, Random House, 2001 (\$24.95).

Within the genre of "books by physicians" one encounters everything from biography, through medicine for the layman, to simply a second interest in writing. The present title is not about signaling among cells (which is in vogue in cell biology) but rather observations on people and life by someone who happened to devote his professional activity to the cellular level. The author is a widely published surgical pathologist who had his formative years in Canada, engaged in specialty training in New York and Los Angeles, and then, for the bulk of his career, was employed by a large community hospital in Southern California.

The book consists of eight essays, all written in a sensitive and insightful manner. The subjects will conjure up further contemplations in the broad audience for which it seems intended. However, this reviewer had difficulty in finding profound and novel concepts. In the introduction, Spencer Nadler contrasts his "cellular" days behind the microscope with his "whole patient" encounters in the past decade. "The Old Soldier" exemplifies this theme, the author's seeking out patient bonding after so many years peering at slides, and being once removed. This approach has obviously fulfilled the writer, but the average reader may wish for a tad less morbidity.

The format and size of the text make for pleasant reading. The selection of color illustrations, reproductions of microscopic slides according to the essay, makes sense but is largely lost by having them ganged together in the front of the book, after the table of contents, rather than inserted as chapter introductions. This was surely due to an unhappy cost reduction, imposed by the production department.

In Australia in the 1940s and 1950s I recall that it was not uncommon for mothers to consult family doctors on career counseling for their sons and daughters. It was intended to be based on cumulative observations during the pediatric years, on the perceived fitness of their minds and bodies for future activities. At second thought it was not all that quaint, but I doubt that it happens anymore. Perhaps this circumstance pertains because today's medical professionals do not enjoy the community respect of their antecedents, and they are normally not as broadly educated, especially within the humanities. His essays indicate that Dr. Nadler is an exception on both counts.
Wilfred Niels Arnold
Biochemistry \& Molecular Biology
University of Kansas Medical Center 